\title{
Fuelling the Knowledge Economy: the Librarian as Catalyst
}

Linda O'Brien, Griffith University, Meadowbrook, Australia

\section{Introduction}

In 2015, I was invited by eResearch Australasia to deliver a keynote at their biennial conference on eResearch skills development in libraries. As the then Pro Vice Chancellor, Information Services, Griffith University, I had responsibility for the leadership and management of the University's information strategy and services. I was acutely aware of the ways in which knowledge creation, synthesis and dissemination were changing. "Today what we call "knowledge" is constantly being questioned, challenged, rethought and rewritten'. (Edwards et al., 2013, p. 7) in a way not seen before. What did this mean for the role of the librarian? Extinction or evolution? This invitation gave me an opportunity to distil some of my thoughts on the role of the librarian in a knowledge economy.

\section{Value Proposition}

Rapid advances in information technology are profoundly re-shaping the ways in which knowledge is created, communicated, combined and applied. The volume, scope and variety of data becoming available are unprecedented. As library and information professionals, we understand the value of data and information in creating a more prosperous future for all. More specifically we understand how to unlock this value through appropriate information management practises at all stages of the data and information creation, management and dissemination lifecycle. Many of us have been pioneers in recognising the exciting potential of emergent technologies, particularly the Internet, to assist in unlocking this value.

Over the last few years much has been written about the need for library and information professionals to shift from being a knowledge service provider to a collaborative partner. But is being partner enough? When we think of partnerships we think collaboration and cooperation, we think shared outputs or outcomes. My proposition is that if we genuinely believe in the power of knowledge to create a prosperous future, and we have the capabilities to unlock the value of the data and information to fuel the knowledge economy, shouldn't we be moving beyond partnership to catalyse the knowledge economy?

\section{Evolution of the Library Profession}

As a young librarian I was incredibly excited about the promise of the Internet. I did not for one minute see the demise of the library but instead this amazing opportunity to improve access to the world's knowledge. In 1990, the year after AARNet was born, I spoke at the first Australian Library and Information Association Biennial conference. It was a time which I described as one of 'rapid political, social, economic and technological change' (O'Brien, 1990, p. 628). Does this sound familiar? Isn't it still? 
At that time the first iPhone was still 7 years away. The Web was being conceptualised but the Web interface as we know it was still 3 years away, and it was to be a further 8 years before Google was launched. So while technology may have advanced swiftly, the challenge to be innovative and see change as an opportunity has remained as a constant.

It was to be almost 10 years later, in 2000, before the term e-science was first used (later to be called eResearch as it moved beyond the sciences into the social sciences and humanities), heralding a growing realisation of the ways in which technology was transforming the research process. By 2005 I was advocating the need for new partnerships to deliver on the promise of eresearch. I was exploring how, as a library and information professional, we could best add value to research by working across traditional silos as research itself became 'more multidisciplinary, more collaborative, more global, and more dependent on the capabilities offered through advanced networks and large data storage' (O'Brien, 2005, p. 76)

\section{Data as an Opportunity}

And now, ten years further on, no one would dispute that the internet has enabled a truly global economy in which

- Potentially everything is tradeable (Business Council of Australia, 2014, p.3)

- Knowledge and innovation are the key to driving economic and social prosperity

- Data is the new currency (Eggers, Hamel, \& Ali, 2013); and

- Translating research into innovation is a national priority.

In Australia government is now focused on finding ways to drive more industry collaboration and innovative businesses through the application of research.

It is sobering to think that ninety percent of the data in the world today was created in the last two years (Loechner, 2016). And as we move into a world characterised by the 'Internet of thing'", this will only escalate. Data collection and analysis are redefining how we think about ourselves and our world, how we interact, how we work, and how we play.

Information is an immensely valuable resource, which, unlike other resources, grows in value through sharing. And it is a resource which we can now extract value from in ways we'd never imagined. No longer must decisions be formed based only on theory - data can now assist in telling us the real story. Across every field of knowledge there are unimaginable quantities of data, enormous opportunities and untapped potential.

What a wonderful time to be a library and information professional! Imagine the opportunity we have to shape the information ecosystem and to fuel the knowledge economy. Trinity College Dublin Library has an excellent strategic plan in which they make this commitment. Indeed, much has been written over recent years about the role of librarians as partners in the process of knowledge creation and dissemination. 


\section{Librarian as Catalyst}

My premise, however, is broader in its reach. As librarians we not only have an opportunity, but also an obligation, to be a catalyst in fuelling the knowledge economy and in shaping the global information ecosystem to advance research, education, understanding and ultimately prosperity.

So, if we are to do this, how must we approach it? How can we go beyond support, beyond partnerships, to being a catalyst? There are three main ways.

1. Focus on delivering value

When describing the new normal as an era of constant disequilibrium, John Seeley Brown (Neal, 2014 , p. 613) has urged us to reframe our ways of working, our ways of creating value, our ways of innovating.

As librarians, if we commit to ensuring access to, and curation of, the world's knowledge so that future generations can build on what has come before, how can we best shape the global information ecosystem which underpins knowledge creation and dissemination? Where should we put our efforts to catalyse the knowledge economy?

2. Create change to thrive

In preparing for my 1990 conference paper I came across Barrett and his theory about the proactive management of change. I was sold. He sees three ways in which change can be managed (Barrett, 1985, p. 31):

There are three stages or levels at which change can be managed, from the crudest and weakest to the most sophisticated and powerful...

1. Coping with change to survive

2. Capitalising on change to thrive

3. Creating change to triumph.

We need to plan to be in the third category:

3. Do not underestimate our ability to influence

Many of you will have seen the concentric circles which remind us there is that which we can control, that which we can influence, and that which is beyond our ability to change (Pathak, 2011, p. 21). Experience has taught me that the middle space (sphere of influence) is far larger and more powerful than you may think. Building and sustaining networks of smart, connected people whom you can enlist in your cause, or whose cause you can support to achieve your outcomes, is exceptionally powerful.

\section{Conclusion}

There has never been a better time to be a library and information professional. For those considering their career options, or seeking to change career, I would recommend the amazing opportunities offered through library and information science. It is now not only deeply relevant to 
every discipline and every profession, it provides you with a skill and knowledge base with which you can catalyse the power and value of the knowledge economy.

\section{Disclosure statement}

No potential conflict of interest was reported by the author.

\section{References}

Barrett, F.D. (1985) Cambietics: the new science of managing change, Management Decision, 23(5), 25-36.

Business Council of Australia. (2014). Building Australia's comparative advantages. Melbourne: The Council

Edwards, P. N., Jackson, S. J., Chalmers, M. K., Bowker, G. C., Borgman, C. L., Ribes, D., . . Calvert, S. (2013). Knowledge infrastructures: Intellectual frameworks and research challenges. Ann Arbor, MI, USA: Deep Blue. Retrieved from http://hdl.handle.net/2027.42/97552

Eggers, W. D., Hamel, R., \& Ali, A. (2013, July 24). Data as the new currency: Government's role in facilitating the exchange. Retrieved from

https://www2.deloitte.com/insights/us/en/deloittereview/issue-13/data-as-the-new-currency.html

Loechner, J. (2016, December 22). 90\% of today's data created in two years. Retrieved from https://www.mediapost.com/publications/article/291358/90-of-todays-data-created-intwoyears.html

Neal, J. G. (2014). A New Age of Reason for Academic Libraries. College \& Research Libraries, 75(5), 612-615.

O'Brien, Linda (1990). Changing an organisation's culture: enhance your library's ability to change and be innovative. Australian Library and Information Association 1st Biennial Conference. Conference Proceedings, Perth, WA. (Vol. I, pp. 627-640).

O'Brien, Linda (2005). E-Research: An Imperative for Strengthening Institutional Partnerships. EDUCAUSE Review, 40(6), 64-77.

Pathak, H. (2011). Organizational Change. Delhi: Pearson Education India. 